See discussions, stats, and author profiles for this publication at: https://www.researchgate.net/publication/317096587

\title{
Initial investigation of the corrosion stability of craniofacial implants
}

Article in The Journal of prosthetic dentistry · May 2017

DOI: 10.1016/.jprosdent.2017.02.015

\section{CITATIONS}

0

7 authors, including:

- Thamara Beline

University of Campinas

13 PUBLICATIONS 64 CITATIONS

SEE PROFILE

Alvin Wee

Veterans Affairs Nebraska-Western lowa Healthcare System, Omaha, NE 109 PUBLICATIONS 2,015 CITATIONS

SEE PROFILE

\section{READS}

95

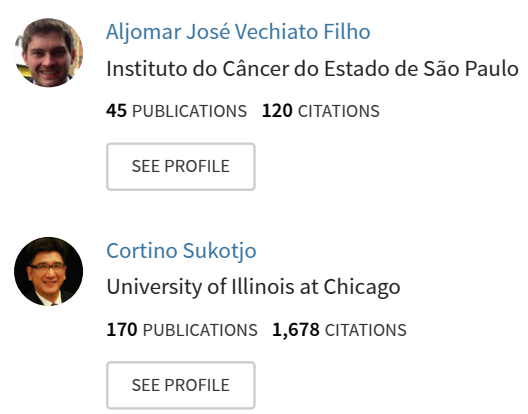

Some of the authors of this publication are also working on these related projects:

Prosthodontic rehabilitation View project

Bioactive coatings produced by plasma electrolytic oxidation (PEO) in Ti-based alloys View project 


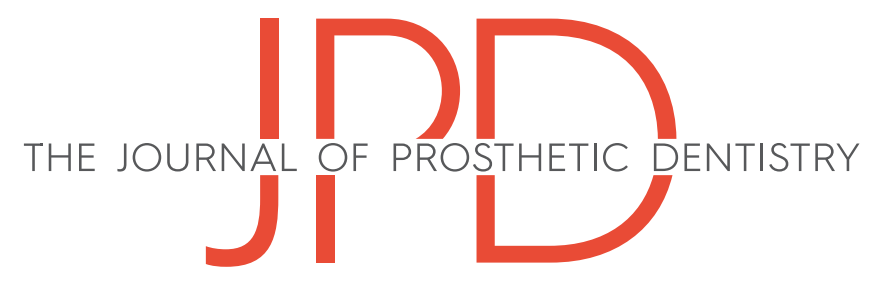

RESEARCH AND EDUCATION

\title{
Initial investigation of the corrosion stability of craniofacial implants
}

\author{
Thamara Beline, DDS, MSc, ${ }^{a}$ Aljomar José Vechiato Filho, DDS, MSc, $\mathrm{PhD}$, \\ Alvin G. Wee, BDS, DDS, MS, MPH, PhD, Cortino Sukotjo, DDS, MMSc, PhD, FACP, \\ Daniela Micheline dos Santos, DDS, MSc, PhD, ${ }^{e}$ Thaís Bianca Brandão, DDS, MSc, ${ }^{f}$ and \\ Valentim Adelino Ricardo Barão, DDS, $\mathrm{MSc} \mathrm{PhD}^{9}$
}

Patients with craniofacial defects can be treated by surgical reconstruction, facial prostheses, or both. ${ }^{1-4}$ Studies have reported that the prosthetic alternative is preferable because surgery may adversely affect patients' psychological well being if its outcome does not match patients' expectations. ${ }^{1,2,4,5}$ Although the appearance of a prosthesis can be enhanced until it meets the patient's approval, these prostheses still face multiple challenges for clinicians and patients, including poor retention. $3,6,7$

In most patients, facial prostheses are retained by skin adhesives. ${ }^{4,7}$ However, perspiration or moisture may negatively affect the bonding between prostheses and the underlying skin, resulting in loss of adhesion. ${ }^{1}$ To overcome this problem, craniofacial implants have

\begin{abstract}
Statement of problem. Although craniofacial implants have been used for retention of facial prostheses, failures are common. Titanium undergoes corrosion in the oral cavity, but the corrosion of craniofacial implants requires evaluation.

Purpose. The purpose of this in vitro study was to investigate the corrosion stability of commercially pure titanium (CP Ti) exposed to simulated human perspiration at 2 different pH levels (5.5 and 8).

Material and methods. Fifteen titanium disks were divided into 3 groups ( $n=5$ per group). The control group was subjected to simulated body fluid (SBF) (control). Disks from the 2 experimental groups were immersed in simulated alkaline perspiration $\left(S A_{K} P\right)$ and simulated acidic perspiration $\left(S A_{C} P\right)$. Electrochemical tests, including open circuit potential (3600 seconds), electrochemical impedance spectroscopy, and potentiodynamic tests were performed according to the standardized method of 3-cell electrodes. Data were analyzed by 1-way ANOVA and the Tukey honestly significant difference tests $(\alpha=.05)$.
\end{abstract}

Results. Simulated human perspiration reduced the corrosion stability of $\mathrm{CP} \mathrm{Ti}(P<.05)$. The SBF group presented the lowest capacitance values $(P<.05)$. $S A_{K} P$ and $S A_{C} P$ groups showed increased values of capacitance and showed no statistically significant differences $(P>.05)$ from each other. The increase in capacitance suggests that the acceleration of the ionic exchanges between the $\mathrm{CP} \mathrm{Ti}$ and the electrolyte leads to a lower corrosion resistance. $\mathrm{SA}_{K} \mathrm{P}$ reduced the oxide layer resistance of $\mathrm{CP} \mathrm{Ti}$ $(P<.05)$, and an increased corrosion rate was noted in both simulated human perspiration groups.

Conclusions. Craniofacial implants can corrode when in contact with simulated human perspiration, whereas alkaline perspiration shows a more deleterious effect. Perspiration induces a more corrosive effect than simulated body fluid. (J Prosthet Dent 2018;119:185-192)

been used to improve prosthesis retention ${ }^{1-4,7}$ and represent the contemporary approach for the

\footnotetext{
Supported by São Paulo Research Foundation, Brazil (grant 2016/07269-3).

${ }^{a}$ Graduate student, Department of Prosthodontics and Periodontology, Piracicaba Dental School, University of Campinas, São Paulo, Brazil.

${ }^{b}$ Assistant, Dental Oncology Service, Institute of Cancer of São Paulo, Faculty of Medicine, University of São Paulo, São Paulo, Brazil.

'Section Head, Maxillofacial Prosthodontics, Veteran's Affairs Nebraska Western lowa Health Care System, Omaha, Neb; and Special Associate Professor,

Department of Prosthodontics, Creighton University School of Dentistry, Omaha, Neb.

${ }^{\mathrm{d}}$ Associate Professor, Department of Restorative Dentistry, University of Illinois at Chicago, College of Dentistry, Chicago, III.

eAssistant Professor, Department of Dental Materials and Prosthodontics, Aracatuba Dental School, São Paulo State University, São Paulo, Brazil.

${ }^{f}$ Coordinator, Dental Oncology Service, Institute of Cancer of São Paulo, Faculty of Medicine, University of São Paulo, São Paulo, Brazil.

${ }^{g}$ Assistant Professor, Department of Prosthodontics and Periodontology, Piracicaba Dental School, University of Campinas, São Paulo, Brazil.
} 


\section{Clinical Implications}

Knowing whether perspiration corrodes craniofacial implants may foster an interest from industry, encourage studies to develop surfaces more resistant to corrosion by perspiration, and lead to more predictable rehabilitation with facial prostheses.

rehabilitation of orbital, auricular, nasal, and multisite facial defects. ${ }^{1,2,8}$

Unfortunately, the success rates of craniofacial implants are lower than those of intraoral implants and vary according to the site of placement. ${ }^{1,2,5,8}$ Clinical data have shown that the quality and volume of the bone, hygiene, radiotherapy, and soft tissue thickness affect the success rates of craniofacial implants. ${ }^{9-12}$ However, such factors do not entirely explain the failure rate of craniofacial implants. Generally, craniofacial implants are placed after radiotherapy and in areas where the volume and quality of the bone are adequate. ${ }^{1,2,4}$ After implant osseointegration, late failure may not be related to the bone tissue quality or to the debilitating toxicities of oncologic treatment performed previously.

The success of dental implant therapy depends not only on the surgical and prosthetic procedures but also on the characteristics of the implant material. ${ }^{13,14}$ The oxide layer characteristics of titanium (Ti) material is governed by the electrochemical properties of the metal, ${ }^{15,16}$ with direct influence on cell viability. ${ }^{17}$ In vitro studies have reported that dental implants can corrode in the oral cavity after exposure to acid substances commonly found in diets, saliva with $\mathrm{pH}$ changes, and microorganisms. ${ }^{13,18-23}$ This process may triggers a cascade of inflammatory events that may lead to bone resorption and implant failure. ${ }^{11,24}$ A study evaluated retrieved intraoral implants and showed that $\mathrm{pH}$ fluctuations were associated with a corrosive process of $\mathrm{Ti}$ surface and consequently implant loss. ${ }^{25}$ Clinically, higher Ti levels are associated with peri-implantitis sites. ${ }^{26,27}$ Unfortunately, to the best of the authors' knowledge, there has been no study investigating retrieved craniofacial implants; however, in evaluating the problem, surface damage due to corrosion may have been overlooked, and craniofacial implants are constantly exposed to body secretions for extended periods. ${ }^{28,29}$

The presence of $\mathrm{NaCl}$ leading to an acceleration of the anodic reaction is the main cause of corrosion processes in metals. ${ }^{30-33}$ As a result, corrosion can be more severe in some regions. ${ }^{34}$ Furthermore, as radiation to the salivary gland can contribute to $\mathrm{pH}$ changes, ${ }^{35}$ patients with head and neck cancer may have altered perspiration $\mathrm{pH}$ after radiotherapy.
Although the corrosive property of Ti may affect the longevity of dental implant treatment, to the best of the authors' knowledge, there has been no investigation of whether human perspiration could induce corrosion of craniofacial implants. Therefore, the purpose of this study was to investigate the corrosion stability of commercially pure $\mathrm{Ti}(\mathrm{CP} \mathrm{Ti})$ material exposed to simulated human perspiration at 2 different $\mathrm{pH}$ levels (5.5 and 8). The null hypothesis was that simulated human perspiration would not affect the corrosion rate of CP Ti material.

\section{MATERIAL AND METHODS}

Commercially pure Ti disks (American Society for Testing and Materials [ASTM] grade 2 titanium [MacMaster Carr]; 15-mm diameter; 2-mm thick) were divided into 3 groups ( $\mathrm{n}=5$ per group), according to different electrolyte types: simulated body fluid (SBF; control), simulated alkaline perspiration $\left(\mathrm{SA}_{\mathrm{K}} \mathrm{P}\right)$, and simulated acidic perspiration $\left(\mathrm{SA}_{\mathrm{C}} \mathrm{P}\right)$. Simulated body fluid was used as a control because it simulates the plasma from human blood, and implants are constantly in contact with such fluid.

All specimens were polished with sequential grit abrasive papers (\#320, \#400, and \#600; CarbiMet 2; Buehler) in an automatic polishing machine (EcoMet/ AutoMet 250 Pro; Buehler) at 250 rpm for 1 minute, ultrasonically cleaned with deionized water and $70 \%$ propanol (2-Propanol; Sigma-Aldrich; 10 minutes), and dried with warm air at $250^{\circ} \mathrm{C} .{ }^{36}$

The electrochemical tests were performed in an electrochemical cell made of polysulfone (Fig. 1). All measurements were performed by a standardized method of 3 -cell electrodes in accordance with the ASTM instructions (G61-86 and G31-72). ${ }^{37}$ The exposed area of the CP Ti disk $\left(2.04 \mathrm{~cm}^{2}\right)$ was estimated by atomic force microscopy/scanning probe microscopy (AFM/SPM) (5500 AFM/SPM; Agilent Technologies) and used as a working electrode. The potentials were measured relative to that of the saturated calomel electrode (reference electrode; Gamry Instruments), and a graphite rod was used as the counter electrode (graphite rod; Gamry Instruments). For the corrosion measurements, a potentiostat (Interface 1000; Gamry Instruments) connected to a computer was used. For each corrosion test, $10 \mathrm{~mL}$ of electrolyte solution $\left(\mathrm{SBF}, \mathrm{SA}_{K} \mathrm{P}\right.$, or $\left.\mathrm{SA}_{C} \mathrm{P}\right)$ was used. The composition of the SBF was $12.0045 \mathrm{~g} / \mathrm{L} \mathrm{NaCl}, 0.5025 \mathrm{~g} / \mathrm{L}$ $\mathrm{NaHCO}_{3}, 0.3360 \mathrm{~g} / \mathrm{L} \mathrm{KCl}, 0.2610 \mathrm{~g} / \mathrm{L} \mathrm{K}_{2} \mathrm{HPO}_{4}, 0.1065 \mathrm{~g} / \mathrm{L}$ $\mathrm{Na}_{2} \mathrm{SO}_{4}, \quad 0.5520 \quad \mathrm{~g} / \mathrm{L} \quad \mathrm{CaCl}_{2} \cdot 2 \mathrm{H}_{2} \mathrm{O}, \quad 0.4575 \quad \mathrm{~g} / \mathrm{L}$ $\mathrm{MgCl}_{2} \cdot \mathrm{H}_{2} \mathrm{O}$, and $60 \mathrm{~mL}$ of $1 \mathrm{M} \mathrm{HCl}{ }^{38}$ Trizma base $\left(\mathrm{C}_{4} \mathrm{H}_{11} \mathrm{NO}_{3}\right)$ was used to achieve a $\mathrm{pH}$ of 7.4. The $\mathrm{SA}_{\mathrm{K}} \mathrm{P}$ solution $(\mathrm{pH}=8.0)$ was prepared by dissolution of $0.5 \mathrm{~g}$ of L-histidine monohydrochloride monohydrate, $5 \mathrm{~g}$ of $\mathrm{NaCl}$, and $5 \mathrm{~g}$ of disodium hydrogen orthophosphate dodecahydrate in $1 \mathrm{~L}$ of distilled water. The composition of $\mathrm{SA}_{\mathrm{C}} \mathrm{P}$ solution $(\mathrm{pH}=5.5)$ was $0.5 \mathrm{~g} / \mathrm{L}$ L-histidine 

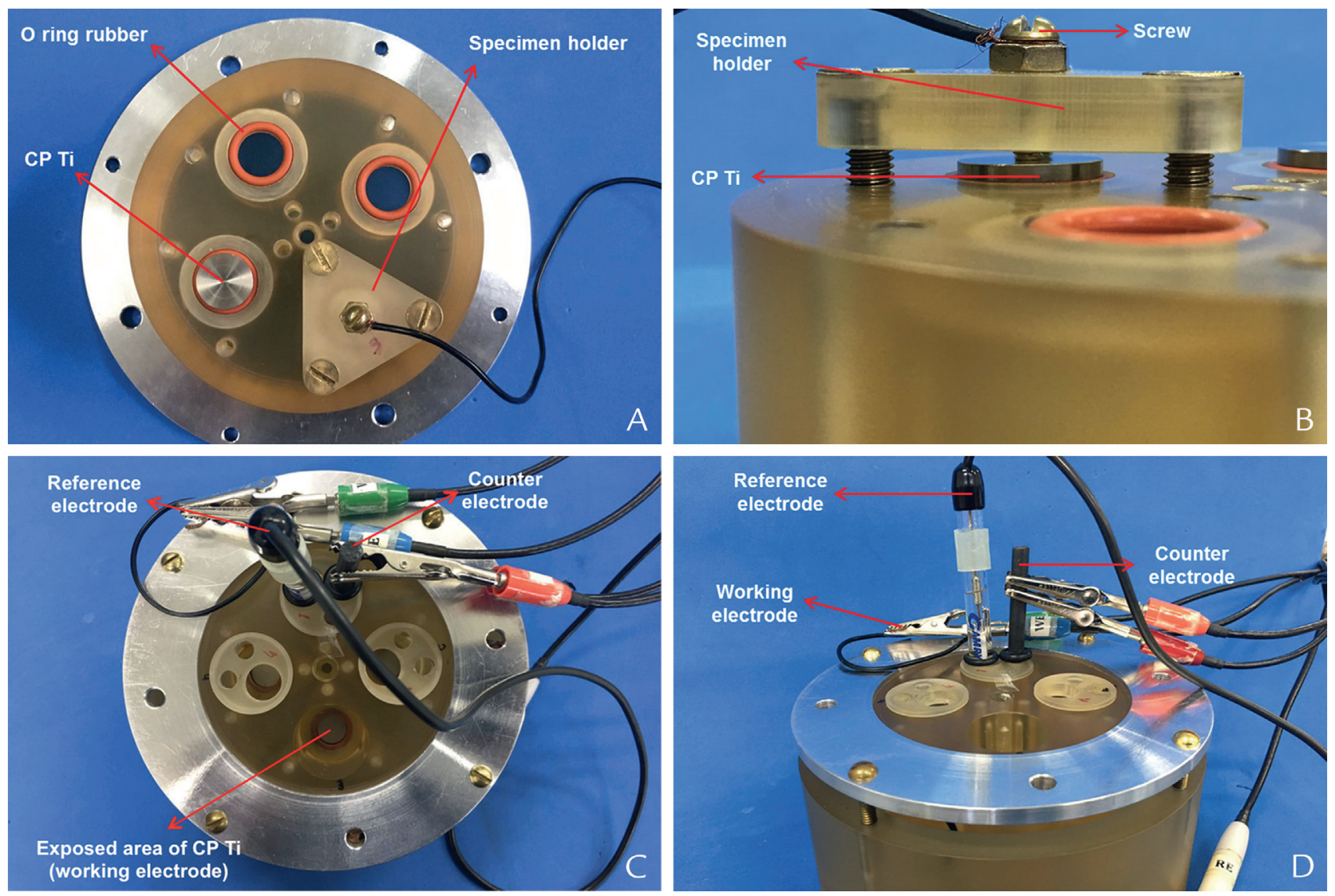

Figure 1. Electrochemical cell. A, Bottom view. B, Specimen holder. C, Top view. Reference electrode, auxiliary electrode, and exposed area of CP Ti (working electrode) are shown. D, Front view. CP Ti, commercially pure titanium.

monohydrochloride monohydrate, $5 \mathrm{~g} / \mathrm{L} \mathrm{NaCl}$, and $2.2 \mathrm{~g} / \mathrm{L}$ sodium dihydrogen orthophosphate dehydrate (all chemicals were purchased from Sigma-Aldrich). The $\mathrm{pH}$ levels used were based on those described in previous in vitro studies ${ }^{28,29}$ in which such solutions were prepared according to International Organization for Standardization specification 105-E04:87, Textiles-Tests for color fastness, Part E04: Color fastness to perspiration, which tests all types of human perspiration. ${ }^{39}$ During the test, the electrolyte temperature was maintained at $37^{\circ} \mathrm{C} \pm 1^{\circ} \mathrm{C}$.

Nine different dependent variables were obtained from the corrosion test: open circuit potential (OCP; potential measured when no current is flowing), polarization resistance $\left(\mathrm{R}_{\mathrm{p}}\right.$; resistance of the specimen to oxidation during the application of an external potential), constant phase element $(\mathrm{CPE})$, corrosion potential ( $\mathrm{E}_{\mathrm{corr}}$; potential at which the rate of oxidation is exactly equal to the rate of reduction), corrosion current density ( $\mathrm{I}_{\text {corr }}$; current flow at the open circuit potential as a result of discrete oxidation or reduction reactions), anodic $\left(\beta_{\mathrm{a}}\right)$ and cathodic $\left(\beta_{\mathrm{c}}\right)$ Tafel slopes, passivation current density $\left(\mathrm{I}_{\text {pass }}\right)$, and corrosion rate (calculated rate of specimen consumption due to homogeneous oxidation). First, a cathodic potential (-0.9 V) was applied for 10 minutes to standardize the oxide layer of the CP Ti surface. The OCP was monitored for a period of 3600 seconds for evaluation of the free corrosion potential of the material in each electrolyte solution. To investigate the formation and growth of the oxide layer on the $\mathrm{CP} \mathrm{Ti}$ surface and its properties, electrochemical impedance spectroscopy (EIS) was used. The EIS measurements were conducted at a frequency range of 100 $\mathrm{kHz}$ to $5 \mathrm{mHz}$, with a sinusoidal amplitude curve of $10 \mathrm{mV}$ applied to the electrode at its corrosion potential ( $\left.\mathrm{E}_{\text {corr }}\right){ }^{40}$ Electrochemical impedance spectroscopy data were used to determine the real $\left(Z_{\text {real }}\right)$ and imaginary $\left(Z_{\text {imag }}\right)$ components of the impedance that corresponded to the current that was in-phase and 90 degrees out-of-phase with the sinusoidally varying voltages, which were presented as Nyquist and Bode $(|Z|)$ plots and phase angle. Electrochemical software (Echem Analyst; Gamry Instruments) was used to analyze the EIS results. Afterward, the specimens were polarized from $-0.8 \mathrm{~V}$ to $1.8 \mathrm{~V}(2 \mathrm{mV} /$ second scan rate). ${ }^{30,36,37}$ The polarization curves by the Tafel extrapolation method provided electrochemical parameters, $\mathrm{E}_{\text {corr }}, \mathrm{I}_{\text {corr }}$ and Tafel slopes $\left(\beta_{\mathrm{a}}\right.$ and $\left.\beta_{\mathrm{c}}\right)$, using electrochemical software (Echem Analyst; Gamry Instruments). The Tafel approximation is a linear fit to the cathodic and anodic polarization curves in the corrosion 


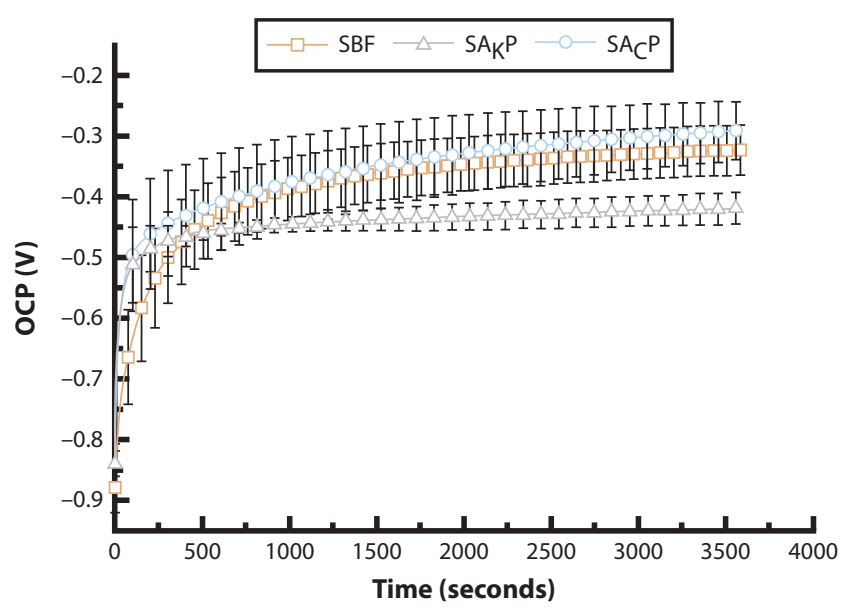

Figure 2. Evolution of open circuit potential (OCP) (V) for 3600 seconds for CP Ti immersed in simulated body fluid (SBF), simulated alkaline perspiration $\left(\mathrm{SA}_{K} \mathrm{P}\right)$, and simulated acidic perspiration $\left(\mathrm{SA} \mathrm{A}_{C} \mathrm{P}\right)$. $\mathrm{CP} \mathrm{Ti}$, commercially pure titanium.

potential. ${ }^{41}$ For corrosion rate estimation, the software used the following formula $\left[C R=\frac{I c o r r}{d A} \cdot E W\right]$, where $\mathrm{I}_{\text {corr }}$ is the corrosion current in amperes, $\mathrm{K}$ is a constant that defines the units of the corrosion rate, EW is the equivalent weight in grams/equivalent, $d$ is the density in $\mathrm{g} / \mathrm{cm}^{3}$, and A is the specimen area in $\mathrm{cm}^{2} .{ }^{42}$ Commercially pure Ti surface was characterized by scanning electron microscopy (model JSM 5600LV; Jeol) and energy dispersive spectroscopy (EDS).

The Shapiro-Wilk method was used to test the normality of all data. The Levene test ensured the equality of variances for all dependent variables. To evaluate the effects of electrolyte type (3 levels) on the electrochemical behavior of $\mathrm{CP} \mathrm{Ti}$, 1-way ANOVA was performed. One-way ANOVA (4 levels) was used to test the differences of CP Ti surface composition before (noncorroded) and after corrosion. The Tukey honestly significant difference (HSD) test was used as a post hoc technique for multiple comparisons $(\alpha=.05)$. Eta squared $\left(\eta^{2}\right)$ was used to estimate the effect size. With 5 specimens per group, a large size effect was obtained for all dependent variables: $\eta^{2}>.26, P<.001$. Statistical software (IBM SPSS Statistics v.20.0; IBM Corp) was used for the analyses.

\section{RESULTS}

The OCP evolution as a function of time is shown in Figure 2. The SBF and $\mathrm{SA}_{C} \mathrm{P}$ groups exhibited the most positive values of OCP and showed no statistically significant differences from each other $(P>.05)$, whereas the $\mathrm{SA}_{K} \mathrm{P}$ group showed the lowest values $(P<.05)$ (Table 1$)$. The evolution of resultant impedance as a function of $Z_{\text {real }}$ and $Z_{\text {img }}$ components is represented by a Nyquist plot (Fig. 3). Specimens immersed in $\mathrm{SA}_{K} \mathrm{P}$ and $\mathrm{SA}_{C} \mathrm{P}$ solutions had a decrease in the semicircular diameter of
Table 1. Mean \pm SD electrochemical impedance spectroscopy parameters obtained from equivalent circuit models for all groups

\begin{tabular}{|c|c|c|c|c|c|}
\hline Group & OCP $(m V)$ & $\frac{R_{p}}{\left(\mathrm{M} \Omega \cdot \mathrm{cm}^{2}\right)}$ & $\frac{\mathrm{CPE} \times 10^{4}}{\left(\mathrm{n} \Omega^{-1} \cdot \mathrm{s}^{\mathrm{n}} \cdot \mathrm{cm}^{-2}\right)}$ & $\eta$ & $\chi^{2} \times 10^{-3}$ \\
\hline SBF & $-322.62 \pm 40.61^{a}$ & $0.78 \pm 0.22^{\mathrm{a}}$ & $3.18 \pm 0.27^{a}$ & $0.92 \pm 0.01$ & $6.73 \pm 2.03$ \\
\hline $\mathrm{SA}_{K} \mathrm{P}$ & $-416.04 \pm 23.16^{b}$ & $0.32 \pm 0.05^{\mathrm{b}}$ & $3.99 \pm 0.34^{b}$ & $0.91 \pm 0.01$ & $50.34 \pm 8.17$ \\
\hline $\mathrm{SA}_{C} \mathrm{P}$ & $-289.98 \pm 48.10^{a}$ & $0.43 \pm 0.09^{c}$ & $3.98 \pm 0.17^{b}$ & $0.94 \pm 0.01$ & $5.36 \pm 0.35$ \\
\hline
\end{tabular}

$S A_{C} P$, simulated acidic perspiration; $S A_{K} P$, simulated alkaline perspiration $S B F$, simulated body fluid. Different superscript letters indicate significant differences among groups for each dependent variable $(P<.05$, Tukey honest significant difference test).

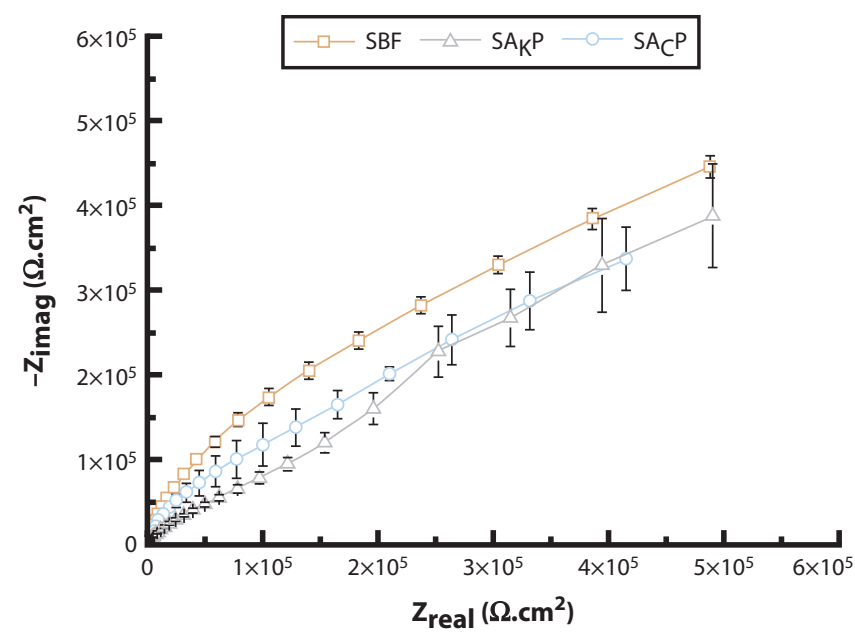

Figure 3. Nyquist diagrams of electrochemical impedance spectroscopy responses of $\mathrm{CP}$ Ti immersed in simulated body fluid (SBF), simulated alkaline perspiration $\left(S_{K} P\right)$, and simulated acidic perspiration $\left(S A_{C} P\right)$. CP $\mathrm{Ti}$, commercially pure titanium; $Z_{\text {imag, }}$ imaginary impedance values; $Z_{\text {real, }}$ real impedance values.

the capacitance loop, whereas specimens immersed in SBF had an increase in the semicircular diameter of the capacitance loop.

The variation in impedance as a function of frequency of the electrochemical double layer formed at the interface of $\mathrm{CP} \mathrm{Ti}$ during the corrosion process was provided by Bode plots (Fig. 4). The SBF group exhibited the highest impedance values compared with those of the $\mathrm{SA}_{K} \mathrm{P}$ and $\mathrm{SA}_{\mathrm{C}} \mathrm{P}$ groups, which presented the lowest and similar impedance values. At phase angle, all groups exhibited only 1 time constant. The $\mathrm{SA}_{K} \mathrm{P}$ group exhibited a slightly smaller phase angle than the other groups. For simulation of the oxide layer properties, a Randles electrical circuit was adopted, ${ }^{19}$ consisting of solution resistance $\left(\mathrm{R}_{\mathrm{sol}}\right), \mathrm{R}_{\mathrm{p}}$, and CPE (Fig. 5). Constant phase element represents the electric double-layer capacitance and is an important parameter that reflects the water absorption in the oxide layer. ${ }^{14}$ Therefore, capacitance was replaced by the CPE for good fit and to minimize the surface heterogeneity factor. ${ }^{23}$ The SBF group showed the highest $R_{p}$ values, whereas the $\mathrm{SA}_{K} \mathrm{P}$ group showed the lowest $(P<.05)$. Regarding capacitance, the SBF group presented the lowest capacitance values $(P<.05)$. The $\mathrm{SA}_{K} \mathrm{P}$ and $\mathrm{SA}_{\mathrm{C}} \mathrm{P}$ 


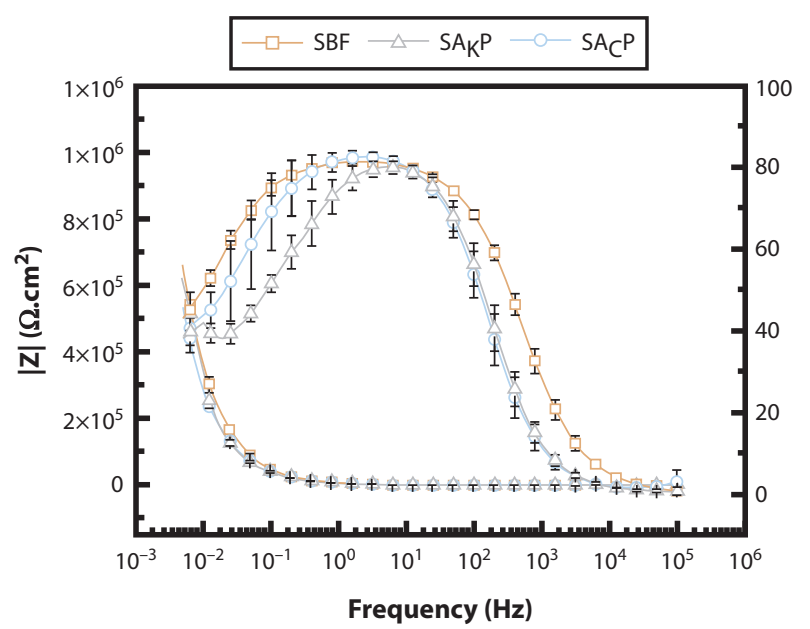

Figure 4. Bode plots from electrochemical impedance spectroscopy recorded for $\mathrm{CP}$ Ti immersed in simulated body fluid $(\mathrm{SBF})$, simulated alkaline perspiration $\left(S A_{K} P\right)$, and simulated acidic perspiration $\left(S A_{C} P\right)$. $C P$ $\mathrm{Ti}$, commercially pure titanium; $|\mathrm{Z}|$, impedance value.

groups increased the values of capacitance with no statistically significant differences between each other $(P>.05)$ (Table 1).

A similar passivation plateau can be observed for all groups in cyclic polarization curves (Fig. 6). The slight shift of the curve to the upper left area of the graph indicates a less active character of the SBF group than that of the $\mathrm{SA}_{K} \mathrm{P}$ and $\mathrm{SA}_{\mathrm{C}} \mathrm{P}$ groups. $\mathrm{SA}_{\mathrm{C}} \mathrm{P}$ and $\mathrm{SA}_{\mathrm{K}} \mathrm{P}$ solutions significantly increased the values of $\mathrm{I}_{\text {corr }}$ and corrosion rate compared with those of the control group $(P<.05)$. The $\mathrm{SA}_{K} \mathrm{P}$ group showed increased values of $\beta_{a}$ Tafel slope compared with those of the other groups $(P<.05)$. The $\mathrm{E}_{\mathrm{corr}} \beta_{\mathrm{c}}$ Tafel slope, and $\mathrm{I}_{\text {pass }}$ values were similar among groups $(P>.05)$ (Table 2$)$.

Scanning electron micrographs showed no clear evidence of change on $\mathrm{CP}$ Ti surface (Fig. 7). Energy dispersive spectroscopy analysis showed that the immersion of $\mathrm{CP} \mathrm{Ti}$ in perspiration solutions slightly reduced the perceptual weight of Ti content compared with noncorroded and SBF groups $(P<.05)$ (Table 3).

\section{DISCUSSION}

The results led to the rejection of the null hypothesis that simulated human perspiration would not affect the electrochemical behavior of $\mathrm{CP}$ Ti. The SBF group showed the highest OCP values, which suggested better corrosion protection than the other 2 groups. ${ }^{19}$ The $\mathrm{SA}_{K} \mathrm{P}$ group exhibited more negative values, indicating less corrosion resistance of $\mathrm{CP}$ Ti when immersed in alkaline perspiration.

Regarding EIS data, the phase angle plot showed just 1 time constant for all groups, suggesting the formation of a homogeneous and compact oxide film on the $\mathrm{CP} \mathrm{Ti}$ surface. The phase angle is usually used to evaluate the

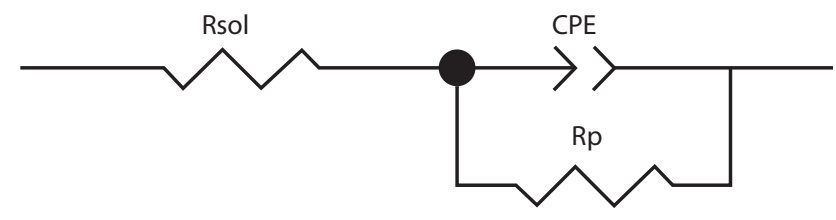

Figure 5. Randles equivalent circuit used for electrochemical impedance spectroscopy data, which shows resistance of solution $\left(R_{\text {sol }}\right)$ in series with parallel combination of constant phase element (CPE) and polarization resistance $\left(R_{p}\right)$ of oxide layer.

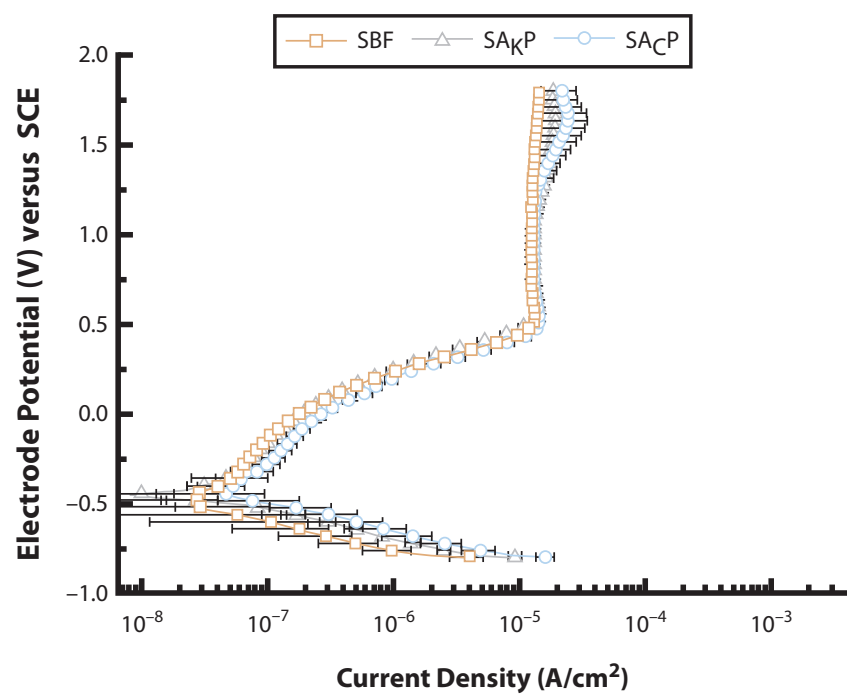

Figure 6. Cyclic potentiodynamic polarization curve of $\mathrm{CP}$ Ti immersed in simulated body fluid (SBF), simulated alkaline perspiration $\left(\mathrm{SA}_{K} \mathrm{P}\right)$, and simulated acidic perspiration $\left(S A_{C} P\right)$. Electrode potential expressed in $\mathrm{V}$ versus saturated calomel electrode.

difficulty of charge transfer in the corrosion reaction process. The charge transfer is relatively facile during the corrosion process when the deviation of phase angle from 90 degrees (an ideal capacitor) occurs. ${ }^{31}$ The $\mathrm{SA}_{K} \mathrm{P}$ group showed reduced phase angles at high frequency compared with the SBF group, which corroborates the high corrosion rate values exhibited by the $\mathrm{SA}_{K} \mathrm{P}$ group. When increases in resistance values and decreases in capacitance values occur, the phase angle increases. ${ }^{40}$

The decrease in the diameter of the semicircular loop in the Nyquist plot for $\mathrm{SA}_{K} \mathrm{P}$ and $\mathrm{SA}_{C} \mathrm{P}$ groups reduced the passive film resistance, indicating that the oxide film that formed on the surface of CP Ti became thinner. If it is thinner, the pitting potential is higher because solutions penetrate more easily. ${ }^{35}$ As a consequence, the electrochemical stability of $\mathrm{CP}$ Ti is also affected..$^{21}$ The SBF group showed better corrosion resistance of $\mathrm{CP} \mathrm{Ti}$ because of the increase in the diameter of the semicircular capacitance loop.

The results previously described are in agreement with polarization resistance and capacitance data, supporting the fact that simulated perspiration solutions have negative effects on the electrochemical behavior 
Table 2. Mean $\pm S D$ values of electrochemical parameters obtained from potentiodynamic polarization curves

\begin{tabular}{|c|c|c|c|c|c|c|}
\hline Group & $E_{\text {corr }}(V)$ & $I_{\text {corr }}\left(\mathrm{nA} \cdot \mathrm{cm}^{-2}\right)$ & $\beta_{\mathrm{a}}\left(\mathrm{V} \cdot \operatorname{dec}^{-1}\right)$ & $-\beta_{\mathrm{c}}\left(\mathrm{V} \cdot \mathrm{dec}^{-1}\right)$ & $I_{\text {pass }}\left(\mu A \cdot \mathbf{c m}^{-2}\right)$ & Corrosion Rate $\times 10^{-2}(\mathrm{mpy})$ \\
\hline SBF & $-0.52 \pm 0.05^{\mathrm{a}}$ & $25.90 \pm 4.20^{\mathrm{a}}$ & $0.57 \pm 0.04^{\mathrm{a}}$ & $0.15 \pm 0.02^{\mathrm{a}}$ & $13.06 \pm 0.59^{\mathrm{a}}$ & $0.50 \pm 0.09^{\mathrm{a}}$ \\
\hline$S A_{K} P$ & $-0.45 \pm 0.01^{\mathrm{a}}$ & $48.96 \pm 5.98^{\mathrm{b}}$ & $0.95 \pm 0.21^{\mathrm{b}}$ & $0.17 \pm 0.02^{\mathrm{a}}$ & $14.14 \pm 0.68^{\mathrm{a}}$ & $1.00 \pm 0.10^{b}$ \\
\hline $\mathrm{SA}_{C} \mathrm{P}$ & $-0.44 \pm 0.05^{\mathrm{a}}$ & $44.65 \pm 5.59^{b}$ & $0.50 \pm 0.06^{\mathrm{a}}$ & $0.16 \pm 0.01^{\mathrm{a}}$ & $14.03 \pm 0.78^{\mathrm{a}}$ & $0.90 \pm 0.10^{b}$ \\
\hline
\end{tabular}

$\mathrm{SA}_{\mathrm{C}} \mathrm{P}$, simulated acidic perspiration; $\mathrm{SA} \mathrm{A}_{\mathrm{K}} \mathrm{P}$, simulated alkaline perspiration $\mathrm{SBF}$, simulated body fluid. Different superscript letters indicate significant differences among groups for each dependent variable $(P<.05$, Tukey honest significant difference test).
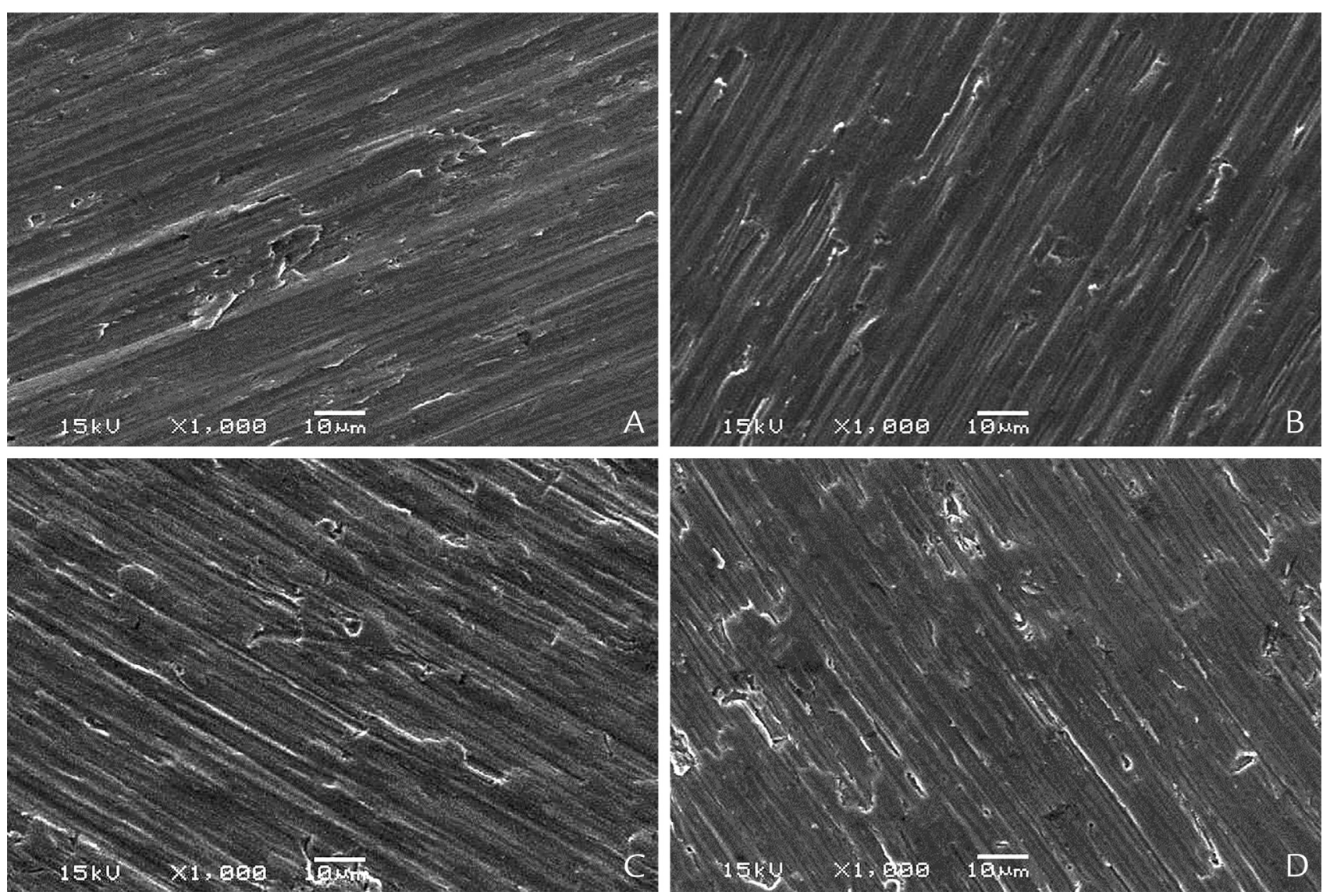

Figure 7. Scanning electron microscopy micrographs (original magnification $\times 1000$ ) of CP Ti surface before and after electrochemical test in electrolyte solutions. A, Noncorroded. B, Simulated body fluid (SBF). C, Simulated alkaline perspiration $\left(S A_{K} P\right)$. D, Simulated acidic perspiration (SA $A_{C}$ ). $C P$ Ti, commercially pure titanium.

of $\mathrm{CP}$ Ti. The immersion of $\mathrm{CP}$ Ti in $\mathrm{SA}_{\mathrm{K}} \mathrm{P}$ solution significantly reduced the $R_{p}$ values of the oxide layer, whereas specimens immersed in SBF exhibited the highest values. These results corroborate $\mathrm{CPE}$ data, where both simulated perspiration solutions increased capacitance values. This event confirms the unfavorable electrochemical behavior of $\mathrm{Ti}$ when subjected to perspiration solutions, because the higher the capacitance, the greater the ion exchange between the material and the electrolyte. ${ }^{36}$

A previous study showed that calcium phosphate deposition promoted lower cathodic reaction and greater polarization resistance. ${ }^{20}$ Therefore, the presence of calcium and phosphate ions in the SBF group explains its improved electrochemical stability over that of simulated perspiration groups. The corrosion resistance of metals
Table 3. Mean \pm SD perceptual weight ( $w t \%)$ values for all groups from EDS analysis

\begin{tabular}{llc}
\hline \multirow{2}{*}{ Group } & \multicolumn{2}{c}{ Chemical elements (wt\%) } \\
\cline { 2 - 3 } Noncorroded & $\mathbf{T i}$ & $\mathbf{S i}$ \\
\hline $\mathrm{SBF}$ & $99.08 \pm 0.50^{\mathrm{a}}$ & $1.14 \pm 0.20^{\mathrm{a}}$ \\
\hline $\mathrm{SA}_{K} \mathrm{P}$ & $97.13 \pm 0.31^{\mathrm{b}}$ & $2.86 \pm 0.31^{\mathrm{b}}$ \\
\hline$S A_{C} \mathrm{P}$ & $96.54 \pm 1.05^{\mathrm{bc}}$ & $3.46 \pm 1.05^{\mathrm{bc}}$ \\
\hline
\end{tabular}

EDS, energy dispersive spectroscopy; $S A_{C} P$, simulated acidic perspiration; $S A_{K} P$, simulated alkaline perspiration SBF, simulated body fluid. Noncorroded, specimens not submitted to electrochemical test. Different superscript letters indicate significant differences among groups for each dependent variable $(P<.05$, Tukey honest significant difference test).

is lower in an environment containing chloride ions. Generally, the $\mathrm{pH}$ of the corroded pit is reduced when the chloride ion concentration increases. ${ }^{33}$ Such behavior may be controversial as the composition of SBF shows 12 
$\mathrm{g}$ of $\mathrm{NaCl}$, whereas only $5 \mathrm{~g}$ are present in the simulated perspiration. However, the simulated perspiration has no calcium and phosphate ions to form a protective layer on the Ti surface, as observed in the SBF group. Therefore, chloride ions may react with $\mathrm{Ti}$ and degrade the $\mathrm{TiO}_{2}$ layer. In further studies, such a mechanism could be better explained by using the Fourier transform infrared spectroscopy technique.

Results of the $\mathrm{I}_{\text {corr }}$ and corrosion rate suggest that perspiration led to greater corrosion of the $\mathrm{CP}$ Ti disks than did the control (SBF). The slight tendency of $\mathrm{SA}_{K} \mathrm{P}$ to exhibit increased $\mathrm{I}_{\text {corr }}$ and corrosion rate values is explained by the higher $\beta_{\mathrm{a}}$ values. Greater $\beta_{\mathrm{a}}$ means higher polarization to achieve the required degree of protection. The higher the value of $\beta_{\mathrm{a}}$ the worse the reduction in the rate of corrosion for a given cathodic polarization. ${ }^{41}$ For the CPE data, both perspiration groups had similar values but significantly higher than the CPE of the SBF group. An increase in capacitance is also associated with a decrease in the thickness of the passive layer over time, which reduces the corrosion stability of $\mathrm{CP} \mathrm{Ti}^{35}$ The similar CPE values between the $\mathrm{SA}_{K} \mathrm{P}$ and $\mathrm{SA}_{\mathrm{C}} \mathrm{P}$ groups may be attributed to the short period of EIS tests (approximately 1 hour).

Scanning electron microscopy analysis showed the absence of pit corrosion and no clear evidence of changes in the CP Ti surface as a result of exposure to simulated perspiration solutions. This observation correlates with a previous study wherein artificial saliva with different $\mathrm{pH}$ values did not affect the surface topography of $\mathrm{Ti}^{36}$ The limited exposure time to the electrolytes may explain the absence of topographical modifications of the Ti surface. The lower content of Ti in the CP Ti surface after exposure to simulated perspiration solutions may be due to the increased $\mathrm{Ti}$ ion released from the surface to the electrolyte. Inductively coupled plasma mass spectrometry should be used to investigate the content of metal ions in the electrolyte solution after electrochemical assay. The presence of $\mathrm{Si}$ in all groups was a result of the sandpaper grit used during the polishing process.

How much changes in the electrochemical parameters would have a clinical relevant effect is difficult to estimate. Clinical studies investigating the influence of current changes and drops in voltages on the longevity of $\mathrm{Ti}$ implants are lacking. In vitro studies have shown that a voltage drop and the electrical field across the metal surface command the oxide layer properties. ${ }^{15,16}$ Periodic cathodic potential changes decrease the polarization resistance values and increase the capacitance values of $\mathrm{CP} \mathrm{Ti}$, while reducing the viability and affecting the morphology of preosteoblast cells. ${ }^{17}$ Therefore, besides the simulated perspiration affecting the electrochemical stability of $\mathrm{CP} \mathrm{Ti}$, the constant influence of such an electrolyte may have clinical relevance in terms of implant longevity. Also, the increase in $\mathrm{I}_{\text {corr }}$ and $\mathrm{CPE}$ values and the reduction in $R_{p}$ values would increase the release of Ti ions to the peri-implant area. Clinical studies have shown that dental implants with peri-implantitis exhibited greater Ti solution levels than healthy implants. ${ }^{26,27}$ Such a finding reveals that Ti ions released from implant surfaces through corrosion pathways are linked to peri-implantitis. However, most of the longitudinal clinical studies of dental and craniofacial implants have overlooked this possible mechanism.

The results of this study may stimulate the industry and researchers to develop surfaces that are more resistant to corrosion by perspiration. Additionally, a multicenter study is encouraged to investigate the possible failure pathways of retrieved craniofacial implants. The present study has some limitations, such as testing only 1 metal implant and limited body fluids. Future experiments using other bodily secretions (such as sebaceous and nasal secretions) could explain the failure mechanisms of facial implants and why the 3 main sites (eye, nose, and ear) have different success rates. Moreover, the development of new corrosion-resistant surface treatments may reduce the incidence of failures and identify the many risk factors for craniofacial implant survival.

\section{CONCLUSIONS}

Within the limitations of this in vitro study, the following conclusions were drawn:

1. Craniofacial implants can corrode when in contact with human perspiration, which is more deleterious than simulated body fluid.

2. The alkaline type had the most corrosive effect when in contact with $\mathrm{CP}$ Ti.

\section{REFERENCES}

1. Karakoca S, Aydin C, Yilmaz H, Bal BT. Retrospective study of treatment outcomes with implant-retained extraoral prostheses: survival rates and prosthetic complications. J Prosthet Dent 2010;103:118-26.

2. Nemli SK, Aydin C, Yilmaz I, Sarisoy S, Kasko Y. Retrospective study of implant-retained orbital prostheses: implant survival and patient satisfaction. J Craniofac Surg 2010;21:1178-83.

3. Pekkan G, Tuna SH, Oghan F. Extraoral prostheses using extraoral implants. Int J Oral Maxillofac Surg 2011:40:378-83.

4. Visser A, Raghoebar GM, van Oort RP, Vissink A. Fate of implant-retained craniofacial prostheses: life span and aftercare. Int J Oral Maxillofac Implants 2008;23:89-98.

5. Atay A, Peker K, Gunay Y, Ebrinc S, Karayazgan B, Uysal O. Assessment of health-related quality of life in Turkish patients with facial prostheses. Health Qual Life Outcomes 2013;11:11.

6. Chang TL, Garrett N, Roumanas E, Beumer J. Treatment satisfaction with facial prostheses. J Prosthet Dent 2005;94:275-80.

7. Nemli SK, Aydin C, Yilmaz H, Bal BT, Arici YK. Quality of life of patients with implant-retained maxillofacial prostheses: a prospective and retrospective study. J Prosthet Dent 2013;109:44-52.

8. Karakoca S, Aydin C, Yilmaz H, Bal BT. Survival rates and periimplant soft tissue evaluation of extraoral implants over a mean follow-up period of three years. J Prosthet Dent 2008;100:458-64.

9. Lundgren S, Moy PK, Beumer J, Lewis S. Surgical considerations for endosseous implants in the craniofacial region-a 3-year report. Int J Oral Maxillofac Surg 1993;22:272-7.

10. Nishimura RD, Roumanas E, Moy PK, Sugai T. Nasal defects and osseoin tegrated implants: UCLA experience. J Prosthet Dent 1996:76:597-602.

11. Nishimura RD, Roumanas E, Sugai T, Moy PK. Auricular prostheses and osseointegrated implants-UCLA experience. J Prosthet Dent 1995;73:553-8. 
12. Roumanas ED, Freymiller EG, Chang TL, Aghaloo T, Beumer J. Implantretained prostheses for facial defects: an up to 14-year follow-up report on the survival rates of implants at UCLA. Int J Prosthodont 2002;15:325-32.

13. Faverani LP, Barao VA, Pires MF, Yuan JC, Sukotjo C, Mathew MT, et al. Corrosion kinetics and topography analysis of Ti-6Al-4V alloy subjected to different mouthwash solutions. Mater Sci Eng C Mater Biol Appl 2014;43: $1-10$.

14. Zhang XM, Wu GS, Peng X, Li LM, Feng HQ, Gao BA, et al. Mitigation of corrosion on magnesium alloy by predesigned surface corrosion. Sci Rep 2015;5:173995.

15. Bearinger JP, Orme CA, Gilbert JL. Direct observation of hydration of $\mathrm{TiO}_{2}$ on Ti using electrochemical AFM: freely corroding versus potentiostatically held conditions. Surf Sci 2001;491:370-87.

16. Bearinger JP, Orme CA, Gilbert JL. In situ imaging and impedance measurements of titanium surfaces using AFM and SPIS. Biomaterials 2003;24: $1837-52$.

17. Ciolko AA, Tobias M, Ehrensberger MT. The effect of fretting associated periodic cathodic potential shifts on the electrochemistry and in vitro biocompatibility of commercially pure titanium. J Biomed Mater Res B Appl Biomater 2016;104:1591-601.

18. Barao VA, Mathew MT, Yuan JC, Knoernschild KL, Assuncao WG, Wimmer MA, et al. Influence of corrosion on lipopolysaccharide affinity for two different titanium materials. J Prosthet Dent 2013;110:462-70.

19. Beline T, Marques Ida S, Matos AO, Ogawa ES, Ricomini-Filho AP, Rangel EC, et al. Production of a biofunctional titanium surface using plasma electrolytic oxidation and glow-discharge plasma for biomedical applications. Biointerphases 2016;11:011013.

20. Cheng $X$, Roscoe SG. Corrosion behavior of titanium in the presence of calcium phosphate and serum proteins. Biomaterials 2005;26:7350-6.

21. Fu T, Zhan Z, Zhang L, Yang Y, Liu Z, Liu J, et al. Effect of surface mechanical attrition treatment on corrosion resistance of commercial pure titanium. Surf Coat Technol 2015;280:129-35.

22. Nakagawa M, Matsuya S, Shiraishi T, Ohta M. Effect of fluoride concentra tion and $\mathrm{pH}$ on corrosion behavior of titanium for dental use. J Dent Res 1999:78:1568-72.

23. Shokouhfar M, Dehghanian C, Montazeri M, Baradaran A. Preparation of ceramic coating on Ti substrate by plasma electrolytic oxidation in different electrolytes and evaluation of its corrosion resistance: part II. Appl Surf Sci 2012;258:2416-23

24. Azzi M, Szpunar JA. Tribo-electrochemical technique for studying tribocorrosion behavior of biomaterials. Biomol Eng 2007;24:443-6.

25. Rodrigues DC, Valderrama P, Wilson TG, Palmer K, Thomas A, Sridhar S, et al. Titanium corrosion mechanisms in the oral environment: a retrieval study. Materials 2013;6:5258-74.

26. Olmedo DG, Nalli G, Verdu S, Paparella ML, Cabrini RL. Exfoliative cytology and titanium dental implants: a pilot study. J Periodontol 2013;84: 78-83

27. Safioti LM, Kotsakis GA, Pozhitkov AE, Chung WO, Daubert DM. Increased levels of dissolved titanium are associated with peri-implantitis-a casecontrol study. J Periodontol 2016:1-12.

28. Hatamleh MM, Watts DC. Effect of extraoral aging conditions on color stability of maxillofacial silicone elastomer. J Prosthodont 2010;19:536-43.
29. Polyzois GL, Tarantili PA, Frangou MJ, Andreopoulos AG. Physical properties of a silicone prosthetic elastomer stored in simulated skin secretions. J Prosthet Dent 2000;83:572-7.

30. Fekry AM, Ghoneim AA, Ameer MA. Electrochemical impedance spectroscopy of chitosan coated magnesium alloys in a synthetic sweat medium. Surf Coat Technol 2014;238:126-32.

31. Feng H, Liu S, Du Y, Lei T, Zeng R, Yuan T. Effect of the second phases on corrosion behavior of the Mg-Al-Zn alloys. J Alloys Compd 2016;695:2330-8.

32. Liang $\mathrm{CH}$, Wang SS, Huang NB, Wang P. Corrosion behavior of brass coinage in synthetic sweat solution. Trans Met Soc China 2015;25:654-60.

33. Ma FY. Pitting corrosion. 1st ed. Rijeka, Croatia: Intech Open; 2012:139-78.

34. Souza ME, Lima L, Lima CR, Zavaglia CA, Freire CM. Effects of pH on the electrochemical behaviour of titanium alloys for implant applications. J Mater Sci Mater Med 2009;20:549-52.

35. Abey S, Mathew MT, Lee DJ, Knoernschild KL, Wimmer MA, Sukotjo C. Electrochemical behavior of titanium in artificial saliva: influence of pH. J Oral Implantol 2014;40:3-10.

36. Barao VA, Mathew MT, Assuncao WG, Yuan JC, Wimmer MA, Sukotjo C. Stability of cp-Ti and Ti-6Al-4V alloy for dental implants as a function of saliva pH - an electrochemical study. Clin Oral Implants Res 2012;23: 1055-62.

37. Barao VA, Ricomini-Filho AP, Faverani LP, Del Bel Cury AA, Sukotjo C, Monteiro DR, et al. The role of nicotine, cotinine and caffeine on the electrochemical behavior and bacterial colonization to cp-Ti. Mater Sci Eng C Mater Biol Appl 2015;56:114-24.

38. Muller L, Muller FA. Preparation of SBF with different HCO3- content and its influence on the composition of biomimetic apatites. Acta Biomater 2006;2: 181-9.

39. Eleni PN, Krokida MK, Polyzois GL, Gettleman L. Material properties of a maxillofacial chlorinated polyethylene elastomer stored in simulated skin secretions. J Biomed Mater Res B Appl Biomater 2009;91B:964-74.

40. Lou XY, Singh PM. Phase angle analysis for stress corrosion cracking of carbon steel in fuel-grade ethanol: experiments and simulation. Electrochim Acta 2011;56:1835-47.

41. Ahmad Z. Principles of corrosion engineering and corrosion control. Oxford, UK: Butterworth-Heinemann; 2006:280-3.

42. Beline T, Garcia CS, Ogawa ES, Marques IS, Matos AO, Sukotjo C, et al Surface treatment influences electrochemical stability of cpTi exposed to mouthwashes. Mater Sci Eng C Mater Biol Appl 2016;59:1079-88.

\section{Corresponding author:}

Dr Valentim Adelino Ricardo Barão

Department of Prosthodontics and Periodontology

University of Campinas (UNICAMP)

Piracicaba Dental School

Av Limeira, 901, Piracicaba

São Paulo, 13414-903

BRAZIL

Email:vbarao@unicamp.br

Copyright () 2017 by the Editorial Council for The Journal of Prosthetic Dentistry. 